\title{
THEIMPACT OF THE COATINGSYSTEM FOR ROLLING STOCK ON FIRE AND ANTI-CORROSION PROPERTIES
}

\author{
doi: $\quad 10.2478 /$ czoto-2019-0101
}

Date of submission of the article to the Editor: 05/11/2018

Date of acceptance of the article by the Editor: 03/02/2019

\author{
Łukasz Pasieczyński ${ }^{1}$ - orcid id: 0000-0002-4983-0684 \\ Norbert Radek ${ }^{2}$ - orcid id:0000-0002-1587-1074 \\ ${ }^{1}$ Firma Handlowa Barwa Jarosław Czajkowski, Poland \\ ${ }^{2}$ Kielce University of Technology, Poland, norrad@tu.kielce.pl
}

\begin{abstract}
Paper discusses results of experimental research aimed at developing of an anti-graffiti paint system for passenger rail vehicles which fulfill the requirements of coating flammability characteristics according to EN 45545-2+A1:2015-12. The most important element of effective fire protection is the use of fire-resistant materials limiting the spread of fire and smoke in rolling stock. Coating system has to meet requirements in the field of fire properties with maintaining the desired performance parameters, such as protective and decorative properties. The development works that are the subject of this article were started by testing standard coating system flammable properties. Next stage of research was to modified fire properties of polyester putty. The tests have shown the effectiveness of the use of a protective paint that allows meeting the requirements in the field of fire safety. In addition, measurements of the corrosion resistance of anti-graffiti coatings were made.
\end{abstract}

Keywords:anti-graffiti, anti-corrosion, fire protection, rolling stock, coating

\section{INTRDUCTION}

European Standard EN 45545-2 (PN-EN 45545, 2015) introduced the need to meet new requirements in terms of fire properties for paint systems. This requirement proved difficult to reconcile with requirements of coatings in the functional scope, i.e. allowing ease of application and maintaining the protective properties as long as possible.The tests included, first of all, parameters such as flame spreading over the surface and heat emission, the fulfillment of which in the previous studies proved the most difficult. There are developed special systems for industrial applications that fulfills requirements of anticorrosive protection which also meet standards for flammability. The development works that are the subject of this article were taken by the F.H. BARWA company in Kielce, while laboratory tests of fire properties were carried out in the Materials and Structure Laboratory of the Railway Institute in Warsaw.Coating systems intended for rolling stock in addition to the above-mentioned requirements, as well as ease of application and operation, must also have adequate 
corrosion resistance. Losses caused by the corrosion affects is an economic problem which has negative influence on the value of national income. If we assume Poland loss only $5 \%$ of GDP, as the cost of corrosion damage and multiply by GDP 2012-2013 (Information Note, 2014) it is estimated at some 20 billion dollars per year.

\section{METHODOLOGY}

The coating was applied with a SATA spray gun on 1.5mm thickness of S335 carbon steel. Before the application the surface of steel was polished with 80-grit sandpaper. The coating system consists of the following layers: anti-corrosion epoxy primer, polyester putty, filler, basecoat and anti-graffiti clearcoat BO100-AGR. Each layer is applied and dried in accordance with the requirements of the technological cards. The prepared samples were conditioned at 23 degrees Celsius and $50 \%$ humidity for minimum 7 days in order to perform tests on the dry coating.

To assess fire resistance, these fire parameters were selected that characterize the material's resistance to external fire sources, i.e.:

1. CFE - critical heat flux, $\mathrm{kW} / \mathrm{m}^{2}$ according to ISO 5658-2 (ISO 5658, 2006) (Fig. 1a),

2. MARHE - maximum average rate of heat release $\mathrm{kW} / \mathrm{m}^{2}$ according to ISO 5660-1 (ISO 5660, 2015) (Fig. 1b).

a)

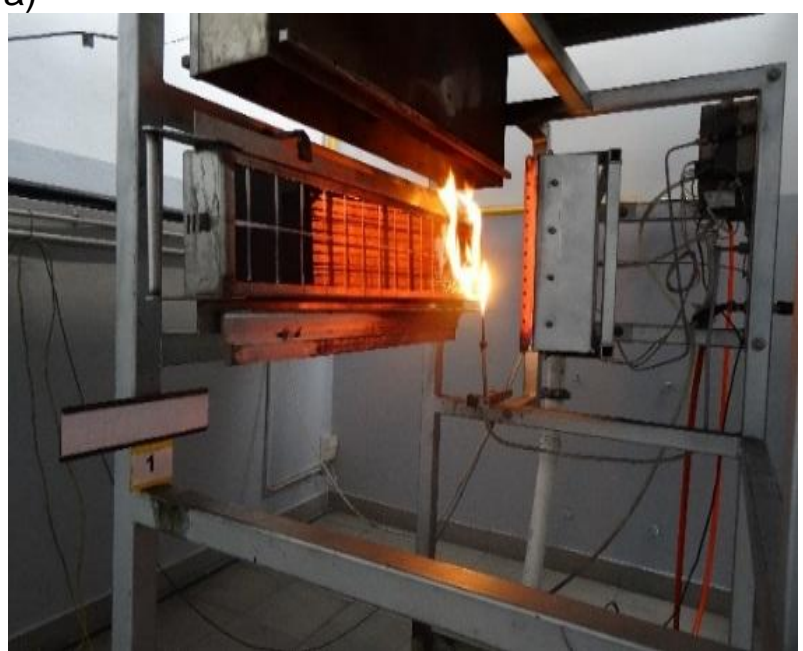

b)

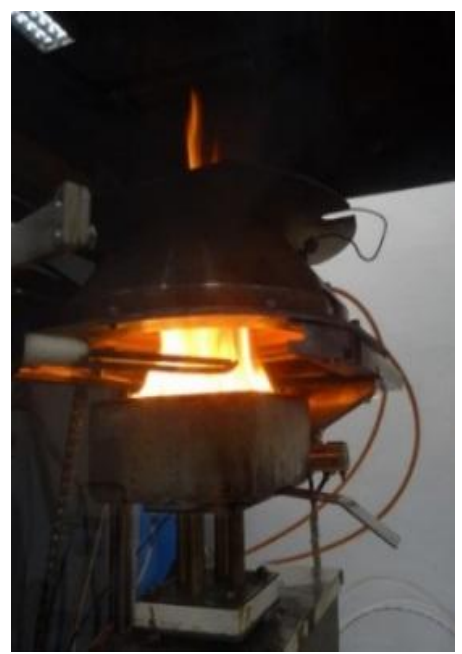

Fig. 1. The sample during test in Railway Institute according to: a) ISO 5658-2, b) ISO 5660-2

Corrosion resistance tests were carried out using the potentiodynamic method. The Autolab PGSTAT100 potentiometer / galvanometer with the FRA2 module was used. The following non-deaerated0.5 molar $\mathrm{NaCl}$ solutions were used for the tests at $25^{\circ} \mathrm{C}$.

\section{RESULTS}

Measurement of dry coating thickness according to PN-EN ISO 2808(PN-EN ISO $2808,2007)$ by magnetic induction. The study was carried out using the Elcometerultrameter. Ten measurements were made on each sample, the results are presented in table 1. 
The test according to ISO 5658-2is performed on three samples with dimensions of $155 \mathrm{~mm} \times 800 \mathrm{~mm}$. This method involves exposing the vertical sample to an external heat flux with a normalized heat density distribution. Results of the test are shown in table 2.

Table 1

Thickness of tested rolling stock coating system

\begin{tabular}{|l|c|c|c|c|}
\hline Product & $\begin{array}{c}\text { Epoxy primer } \\
{[\mu \mathrm{m}]}\end{array}$ & $\begin{array}{c}\text { Polyester putty } \\
{[\mu \mathrm{m}]}\end{array}$ & $\begin{array}{c}\text { Filler } \\
{[\mu \mathrm{m}]}\end{array}$ & $\begin{array}{c}\text { Sum of basecoat } \\
\text { and clearcoat }[\mu \mathrm{m}]\end{array}$ \\
\hline $\begin{array}{l}\text { Average total } \\
\text { thickness }\end{array}$ & 82.4 & 2153.3 & 2221.7 & 2370.8 \\
\hline $\begin{array}{l}\text { Standard } \\
\text { deviation }\end{array}$ & 3.7 & 102.6 & 141.2 & 150.6 \\
\hline
\end{tabular}

Table 2

Results of critical heat flux according to ISO 5658-2

\begin{tabular}{|c|c|c|c|c|c|}
\hline Sample & $\begin{array}{c}\text { Spread of } \\
\text { fire }[\mathbf{m m}]\end{array}$ & $\begin{array}{c}\text { Combustion } \\
\text { time }[\mathbf{s}]\end{array}$ & $\begin{array}{c}\text { CFE } \\
{\left[\mathbf{k W} / \mathbf{m}^{2}\right]}\end{array}$ & $\begin{array}{c}\text { CFE } \\
\text { Average } \\
{\left[\mathbf{k W} / \mathbf{m}^{2}\right]}\end{array}$ & $\begin{array}{c}\text { CFE standard deviation } \\
{\left[\mathbf{k W} / \mathbf{m}^{2}\right]}\end{array}$ \\
\hline 1 & 447 & 755 & 13.6 & \multirow{2}{*}{12.4} & \multirow{2}{*}{1.1} \\
\hline 2 & 469 & 680 & 11.6 & & \\
\hline 3 & 466 & 670 & 11.9 & & \\
\hline
\end{tabular}

The test is carried out using a cone calorimeter, in which the principle of oxygen consumption calorimetry is used.Three $100 \mathrm{~mm}$ x $100 \mathrm{~mm}$ samples are tested. Samples are exposed to a conical shaped electric heater with a radiation intensityof $50 \mathrm{~kW} / \mathrm{m}^{2}$. Ignition of the samples is initiated by a spark igniter and combustion takes place in the atmosphere of air $\left(0.024 \mathrm{~m}^{3} / \mathrm{s}\right)$.MARHE parameter representing the maximum average rate of heat release (ARHE) during 20 minutes of the test calculated according to the (1) formula. Results are presented in table 3 (Pasieczyński et al., 2018a).

$$
\operatorname{ARHE}\left(t_{n}\right)=\frac{\sum_{2}^{n}\left(t_{n}-t_{n-1}\right) \times \frac{q_{n+} q_{n-1}}{2}}{t_{n}-t_{n-1}}
$$

$t$ - time, mostly $t_{1}=0$,

$q$ - heat release rate, mostly $q_{1}=0$.

Table 3

Results of maximum average rate of heat release according to ISO 5660-1

\begin{tabular}{|c|c|c|c|}
\hline Sample & $\begin{array}{c}\text { MARHE } \\
{\left[\mathbf{k W} / \mathbf{m}^{\mathbf{2}}\right]}\end{array}$ & $\begin{array}{c}\text { MARHE Average } \\
{\left[\mathbf{k W} / \mathbf{m}^{2}\right]}\end{array}$ & $\begin{array}{c}\text { MARHE standard deviation } \\
{\left[\mathrm{kW} / \mathbf{m}^{2}\right]}\end{array}$ \\
\hline 1 & 208.1 & \multirow{2}{*}{198.1} & \multirow{2}{*}{9.4} \\
\hline 3 & 196.8 & & \\
\hline 3 & 189.4 & & \\
\hline
\end{tabular}

The values of the specified parameters CFE $\left(\mathrm{kW} / \mathrm{m}^{2}\right)$ and MARHE $\left(\mathrm{kW} / \mathrm{m}^{2}\right)$ were significantly different from the admissible criteria. F.H. BARWA Laboratory started working on the modification of the polyester putty in order to reduce its flammability. 
Thickness of modified coating system are shown in table 4. Modified coating system consists all layers mentioned before with the change of standard putty on developed by laboratory.

Table 4

Thickness of developed rolling stock coating system

\begin{tabular}{|c|c|c|c|c|}
\hline Product & $\begin{array}{c}\text { Epoxy } \\
\text { primer }[\mu \mathrm{m}]\end{array}$ & $\begin{array}{c}\text { Polyester putty } \\
{[\mu \mathrm{m}]}\end{array}$ & $\begin{array}{c}\text { Filler } \\
{[\mu \mathrm{m}]}\end{array}$ & $\begin{array}{c}\text { Sum of basecoat } \\
\text { and clearcoat }[\mu \mathrm{m}]\end{array}$ \\
\hline $\begin{array}{c}\text { Average total } \\
\text { thickness }\end{array}$ & 41.3 & 2088.8 & 2306.3 & 2361.3 \\
\hline Standard deviation & 2.8 & 98.6 & 143.5 & 148.6 \\
\hline
\end{tabular}

A comparison results of flammable properties of standard and modified coating systems are shown in Figure 2 and Figure 3.

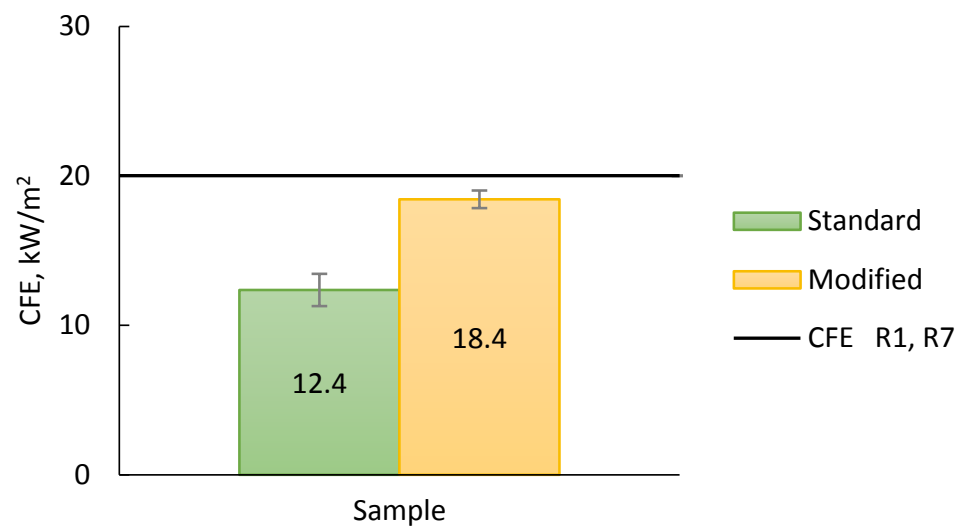

Fig. 2.Comparison of critical heat flux parameters of standard and modified coating system

Prior to electrochemical studies, the samples were exposed to a corrosive solution in current-free conditions for $120 \mathrm{~min}$. Potentiodynamic test were conducted in a threeelectrode setup: the test electrode, reference electrode (saturated calomel electrode (SCE)), auxiliary electrode (platinum), up to a potential of $1800 \mathrm{mV}$, or to reach the currents above $1 \mathrm{~mA} / \mathrm{cm}^{2}$. The test material was polarized with a potential sweep rate of $0,2 \mathrm{mV} / \mathrm{s}$. After 24 hours electrochemical tests marked as exposed were repeated. Results are presented on Figure 5 and table 5 (Pasieczyński et al., 2018b).

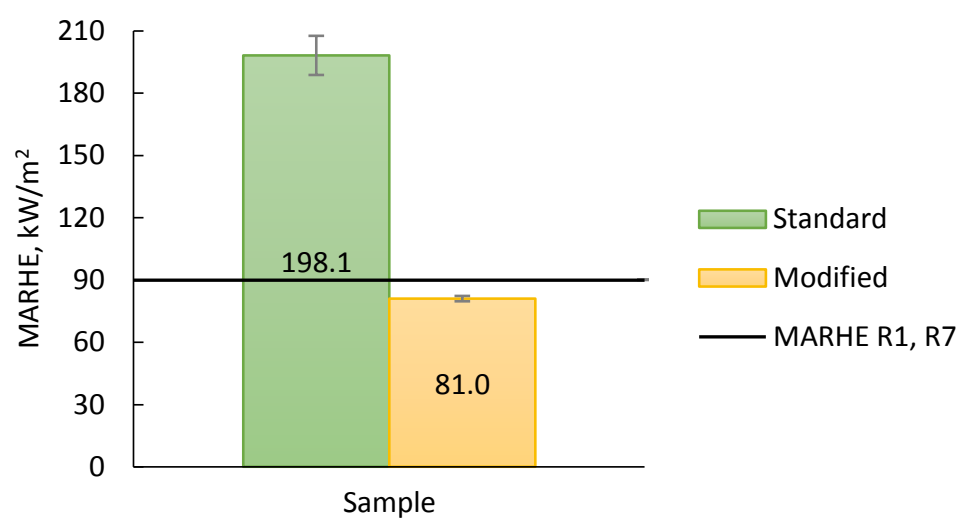

Fig. 3.Comparison of maximum average rate of heat release parameters of standard and modified coating system 
Figure 4 presents Comparison of ARHE results of tested polyester putties in first 400 seconds of the test.

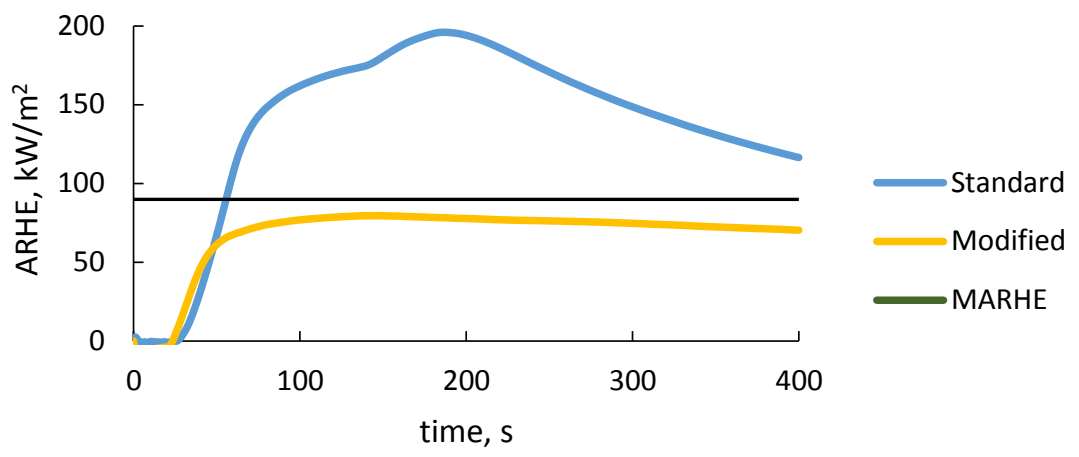

Fig. 4.Average rate of heat release parameters of standard and modified coating system

Table 5

Results of electrochemical studies, potentiodynamic test conducted in $0.5 \mathrm{M} \mathrm{NaCl}$

\begin{tabular}{|c|c|c|c|}
\hline $\mathbf{N a C l}$ & $\mathbf{R t},\left[\mathbf{k} \boldsymbol{\Omega} \mathbf{c m}^{\mathbf{2}}\right]$ & Ekor, $[\mathbf{m V}]$ & $\mathbf{I k o r},\left[\mathbf{\mu A} / \mathbf{c m}^{2}\right]$ \\
\hline Steel & 1.46 & -690 & $1.09 \mathrm{E}+01$ \\
\hline Standard & 1230 & -780 & $1.61 \mathrm{E}-02$ \\
\hline Exposed & 39 & -680 & $3.93 \mathrm{E}-01$ \\
\hline
\end{tabular}

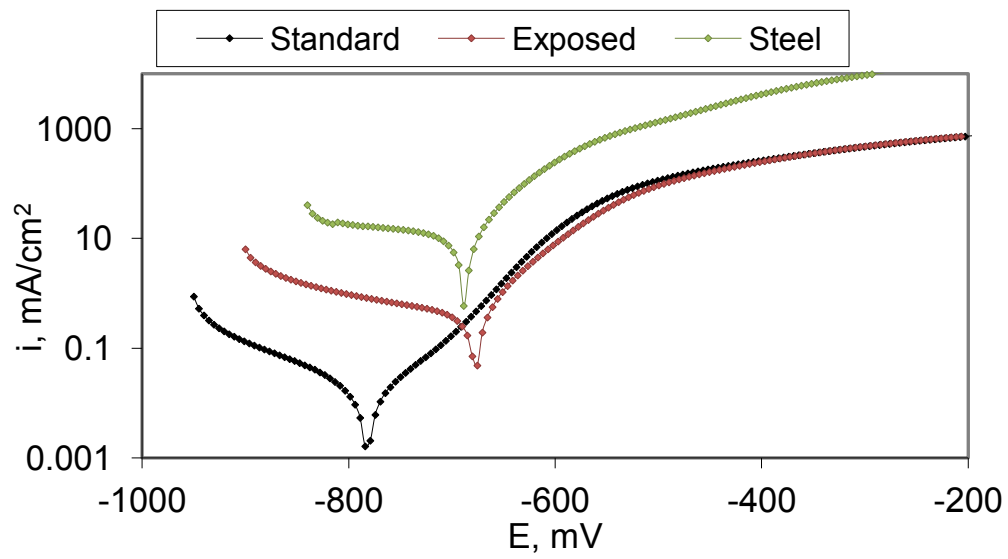

Fig. 5.Polarization curves before and after exposure to the solution of 0,5 molar $\mathrm{NaCl}$

\section{DISCUSSION}

The coating system used today does not meet the requirements of European Union regulation introduced by EN 45545-2 standard. By introduced in the coating system with new putty developed by F.H. BARWA the requirements aren't so far to achieve. MARHE parameters are $10 \%$ lower than European standard requirement. Still some work is need to be done to improve CFE parameters. Standard requirement for vehicle body is above $20 \mathrm{~kW} / \mathrm{m}^{2}$. Developed putty characterized CFE parameters results $18.4 \mathrm{~kW} / \mathrm{m}^{2}, 8 \%$ lower than requirements. During the research, the impact of the thickness of the putty was taken into account by preparing closely similar samples in terms of thickness. Corrosion resistance were performed on coating system with standard putty. In studied solution coating system through its protective properties lower corrosion current, increasing corrosion resistance and vehicle lifetime. More 
research needs to be done with new developed coating system. Polarization curves of coating systems after exposure to the corrosive environment shifted towards higher potentials and higher densities of the corrosive current.

\section{CONCLUSION}

The laboratory tests carried out allow to state that modification of polyester putty of the coating system is the right direction of modification in order to protect the system against fire spread. In the next step, it is planned to perform more resistance tests: humidity resistance, combine corrosion tests and start long-term natural weathering test. It will include various method such as an image analysis (Gadek-Moszczak, 2017), a fuzzy assessment of an uncertainty (Pietraszek, 2012; Pietraszek et al., 2018), a non-parametric modelling of processes (Pietraszek and Gadek-Moszczak, 2013; Gadek-Moszczak et al., 2015) and, at last, the combination of all these methods inside the design of experiment methodology (Skrzypczak-Pietraszek and Pietraszek, 2009; Skrzypczak-Pietraszek et al., 2018a, Skrzypczak-Pietraszek et al., 2018b). It also seems that a FEM-based numerical simulation of the flow (Domagala et al., 2018a; Domagala et al., 2018b) and thermomechanical processes accompanying the fire burning should provide a lot of detailed information, especially related to properties of construction materials and their mutual interactions (Guidoni et al., 2005; Ulewicz et al., 2010; Hebda et al., 2012; Pieczonka et al., 2012; Kapustka et al., 2017; Gawdzinska et al., 2018). The possible results should impact on the quality management systems (Ulewicz, 2016) and process management systems (Ulewicz et al., 2013) in the industry.

\section{REFERENCES}

Domagala, M., Momein, H., Domagala-Fabis, J., Filo, G., Kwiatkowski, D., 2018a. Simulation of Cavitation Erosion in a Hydraulic Valve. Mater. Res. Proc., 5, 1-6.

Domagala, M., Momeni, H., Domagala-Fabis, J., Filo, G., Krawczyk, M., 2018b. Simulation of Particle Erosion in a Hydraulic Valve. Mater. Res. Proc., 5, 17-24.

Gadek-Moszczak, A., 2017. History of stereology. Image Anal. Stereol., 36, 151-152.

Gadek-Moszczak, A., Pietraszek, J., Jasiewicz, B., Sikorska, S., Wojnar, L., 2015. The bootstrap approach to the comparison of two methods applied to the evaluation of the growth index in the analysis of the digital $x$-ray image of a bone regenerate. New Trends in Computational Collective Intelligence, 572, 127-136.

Gawdzinska, K., Gadek-Moszczak, A., Bryll, K., Irska, I., Paszkiewicz, S., 2018. Influence of water absorption on chosen strength properties of single-polymer polyester composites. Polimery, 63, 264-269.

Guidoni, G., Dudek, A., Patsias, S., Anglada, M., 2005. Fracture behaviour of thermal barrier coatings after high temperature exposure in air. Mat. Sci. Eng.A-Struct., 397, 209-214.

Hebda, M., Gadek, S., Kazior, J., 2012.Thermal characteristics and analysis of pyrolysis effects during the mechanical alloying process of AstaloyCrM powders.

J. Therm. Anal.Calorim., 108, 453-460.

Information Note, 2014, Central Statistical Office, Warsaw 2014.

ISO 5658-2:2006 Reaction to fire tests - Spread of flame. Part 2: Lateral spread on building and transport products in vertical configuration. 
ISO 5660-1:2015 Plastics - Reaction-to-fire tests-Heat release, smoke production and mass loss rate - Part 1: Heat release rate (cone calorimeter method) and smoke production rate (dynamic measurement).

Kapustka, K., Ziegmann, G., Sdrenka, S., Elwert, T., Klimecka-Tatar, D., 2017. The characterization of grinded $\mathrm{NdFeB}$ magnetic materials obtained from electric motors. Metal 2017: $26^{\text {th }}$ Int. Conf. Metallurgy and Materials, Ostrava, Tanger, 1757-1762.

Pasieczyński, Ł., Radek, N., Radziszewska-Wolińska, J., 2018a. Fire properties of "anti-graffiti" coating systems for rolling stock. 11th International Scientific and Technical Conference on Automotive Safety, New York, IEEE, 1-5.

Pasieczyński, Ł., Radek, N., Radziszewska-Wolińska, J., 2018b. Operational properties of anti-graffiti coating systems for rolling stock. Advances in Science and Technology - Research Journal, 12(1), 127-134.

Pieczonka, T., Kazior, J., Szewczyk-Nykiel, A., Hebda, M., Nykiel, M., 2012. Effect of atmosphere on sintering of Alumix 431D powder. Powder Metall., 55, 354-360.

Pietraszek, J., 2012. Fuzzy Regression Compared to Classical Experimental Design in the Case of Flywheel Assembly. Artificial Intelligence and Soft Computing, Pt I, 7267, 310-317.

Pietraszek, J., Gadek-Moszczak, A., 2013. The smooth bootstrap approach to the distribution of a shape in the ferritic stainless steel AISI 434L powders. Solid State Phenom., 197, 162-167.

Pietraszek, J., Kolomycki, M., Szczotok, A., Dwornicka, R., 2016. The Fuzzy Approach to Assessment of ANOVA Results. ICCCI 2016, Computational Collective Intelligence Conf., Lecture Notes in Artif.Intell., Springer, 260-268.

PN-EN ISO 2808:2007 Paints and varnishes - Determination of film thickness.

PN-EN 45545-2+A1:2015-12: Railway applications - Fire protection on railway vehicles - Part 2: Requirements for fire behaviour of materials and components.

Skrzypczak-Pietraszek, E., Pietraszek, J., 2009. Phenolic acids in in vitro cultures of Exacum affine Balf. f. Acta Biol.Cracov. Bot., 51, 62-62.

Skrzypczak-Pietraszek, E., Piska, K., Pietraszek, J., 2018a. Enhanced production of the pharmaceutically important polyphenolic compounds in Vitex agnus castus $L$. shoot cultures by precursor feeding strategy. Eng. Life Sci., 18, 287-297.

Skrzypczak-Pietraszek, E., Reiss, K., Zmudzki, P., Pietraszek, J., 2018b. Enhanced accumulation of harpagide and 8-O-acetyl-harpagide in Melittismelissophyllum L. agitated shoot cultures analyzed by UPLC-MS/MS. PLoS ONE 13, e0202556.

Ulewicz, M., Lesinska, U., Bochenska, M., 2010. Transport of lead across polymer inclusion membrane with p-tert-butylcalix[4]arene derivative. Physicochem. Probl. Miner. Process., 44(1), 245-256.

Ulewicz, R., 2016. Quality Management System operation in the woodworking industry. Int. Conf. Path Forward for wood products: a global perspective. Proc. of Sci. Papers, Zagreb, WOODEMA, 51-56.

Ulewicz, R., Selejdak, J., Borkowski, S., Jagusiak-Kocik, M., 2013. Process management in the cast Iron foundry. Metal 2013: $22^{\text {nd }}$ Int. Conf. Metallurgy and Materials, Ostrava, Tanger, 1926-1931. 